\title{
Incidence and Prevalence of Chronic Inflammatory Demyelinating Polyradiculoneuropathy: A Systematic Review and Meta-Analysis
}

\author{
Merel C. Broers ${ }^{a}$ Carina Bunschoten $^{a}$ Daan Nieboer ${ }^{b}$ Hester F. Lingsma ${ }^{b}$ \\ Bart C. Jacobs ${ }^{a, c}$ \\ ${ }^{a}$ Department of Neurology, Erasmus MC, University Medical Center Rotterdam, Rotterdam, The Netherlands; \\ ${ }^{b}$ Department of Public Health, Erasmus MC, University Medical Center Rotterdam, Rotterdam, The Netherlands; \\ 'Department of Immunology, Erasmus MC, University Medical Center Rotterdam, Rotterdam, The Netherlands
}

\section{Keywords}

Chronic inflammatory demyelinating

polyradiculoneuropathy $\cdot$ Incidence $\cdot$ Prevalence .

Systematic review $\cdot$ Meta-analysis

\section{Abstract}

Background: Prevalence and incidence rates of chronic inflammatory demyelinating polyradiculoneuropathy (CIDP) are required to determine the impact of CIDP on society. We aimed to estimate the prevalence and incidence of CIDP worldwide and to determine the effect of diagnostic criteria on prevalence and incidence. Method: A systematic review was conducted for all published incidence and prevalence studies on CIDP until May 18, 2017. Methodological quality was assessed using the Methodological Evaluation of Observational Research checklist. We performed a random effect meta-analysis to estimate pooled prevalence and incidence rates. Results: Of the 907 studies, 11 were included in the systematic review, 5 in the meta-analysis of incidence $(818$ cases; 220,513,514 person-years) and 9 in the meta-analysis of prevalence ( 3,160 cases; $160,765,325$ population). These studies had a moderate quality. The pooled crude incidence rate was 0.33 per 100,000 person-years $(95 \% \mathrm{Cl} 0.21-0.53$;
$\left.R^{2}=95.7 \%\right)$ and the pooled prevalence rate was 2.81 per $100,000\left(95 \% \mathrm{Cl} 1.58-4.39 ; I^{2}=99.1 \%\right)$. Substantial heterogeneity in incidence and prevalence across studies seems to be partly explained by using different diagnostic criteria. Conclusion: These findings provide a starting point to estimate the social burden of CIDP and demonstrate the need to reach consensus on diagnostic criteria for CIDP.

(c) 2019 The Author(s)

Published by S. Karger AG, Basel

\section{Introduction}

Chronic inflammatory demyelinating polyradiculoneuropathy (CIDP) is a disorder of the peripheral nerves and nerve roots causing limb weakness and sensory deficits [1]. CIDP is considered an immune-mediated disorder although the pathogenesis and aetiology of CIDP remain elusive $[2,3]$.

The clinical presentation of CIDP is diverse and at least 15 sets of diagnostic criteria for CIDP have been developed to capture the full spectrum of CIDP and its variant forms [4-7]. The criteria from the European Federation of Neurological Societies and Peripheral Nerve Society (EFNS/ 
PNS) from 2010 are based on a combination of clinical and electrodiagnostic characteristics and are currently the most widely accepted criteria to confirm the diagnosis of CIDP [4]. Proven effective treatments for CIDP are immunoglobulins, corticosteroids and plasmapheresis [8]. The clinical response to these treatments is usually only partial and transient. Most patients with CIDP require maintenance treatment for years or even decades [8]. CIDP is therefore a disabling disorder with a considerable impact on patients and patient-related health care costs [9-14]. However, the population-based burden and related health costs are unknown. To determine this, we need to estimate the incidence and prevalence of CIDP.

Previous reviews provided an overview of studies that investigated the incidence and prevalence of neuromuscular disorders, polyneuropathies and rare diseases in general [15-17]. However, these reviews were not performed to give an overview of the incidence and prevalence of CIDP in specific and no meta-analysis was conducted. Furthermore, the use of different sets of criteria to diagnose CIDP may affect the incidence and prevalence rates [18]. To better estimate the true frequencies, patient numbers of individual studies need to be combined and the incidence and prevalence of CIDP using different diagnostic criteria need to be compared.

Our aim was to conduct a systematic review and metaanalysis to estimate the incidence and prevalence of CIDP worldwide and to determine the effect of diagnostic criteria on reported incidence and prevalence rates.

\section{Method}

This systematic review was performed according to the Preferred Reporting Items for Systematic reviews and Meta-Analyses guidelines [19]. The protocol of this systematic review was registered (registration number 2017: CRD42017072270) in PROSPERO (International prospective register of systematic reviews) [20].

\section{Data Sources and Search Strategy}

One author (M.C.B.) and a biomedical information specialist (Gerdien B. de Jonge) searched in Embase, Medline Epub, Cochrane Central, Web of Science and Google Scholar for all published work until May 18, 2017 (online suppl. Appendix I; for all online suppl. material, see www.karger.com/doi/10.1159/000494291). We used a combination of disease-specific terms (CIDP, chronic inflammatory demyelinating polyneuropathy) and key words for incidence and prevalence (epidemiology, prevalence and incidence). Reference lists of obtained articles were reviewed for additional articles.

Study Selection

We included all studies that reported the prevalence and/or incidence of CIDP and met the following criteria: (1) English language, (2) population based, (3) cases were identified based on fulfilling general accepted diagnostic criteria for CIDP (e.g., 2010 EFNS/PNS criteria, American Academy of Neurology [AAN] criteria) and (4) original data (i.e., not a review or a duplicate of previously published data, and full text must have been published). There were no limitations regarding the study size and identified the number of CIDP cases. We excluded studies that identified cases not based on general accepted diagnostic criteria for CIDP (e.g., insurance administrative medical codes, patient reports, membership patient organization). Studies that reported the prevalence and/or incidence in specific disease groups (e.g., diabetic population) instead of the general population were excluded. Studies that reported age and gender-specific prevalence and/or incidence were included.

Eligibility of all articles was determined by one author (M.C.B.) and independently checked by another author (C.B.). Titles and abstracts of all articles identified by the initial search strategy were independently reviewed on relevance. Articles that obviously did not meet the inclusion criteria were excluded. The full text of the remaining articles was reviewed in detail to assess whether they met the inclusion criteria. In case of disagreement, a third author (B.C.J.) reviewed the article and consensus was reached through discussion.

\section{Data Extraction}

Data of included studies was initially extracted by a single author (M.C.B.) and independently checked by another author (C.B.). Discrepancies were resolved by discussion with a third author (B.C.J.). Extracted information included author, study design, study period, population (study region, population number, person-years, age, CIDP categories), diagnostic criteria used to identify CIDP cases, number of identified CIDP patients, gender ratio, reported incidence rates (crude, standardized, age- and sex adjusted) and reported prevalence rates (crude, standardized, age- en sex adjusted). When data needed for the meta-analysis (cases, population number and person-years) was missing, we asked the corresponding author to provide this additional information.

One author (M.C.B.) assessed the methodological quality and risk of bias of the included studies. The Methodological Evaluation of Observational Research (MORE) checklist [21] was used to verify methodological quality and risk of bias. This checklist was designed for quality and bias assessment in incidence or prevalence studies of chronic diseases, and was previously used in several systematic reviews [22-28]. Two authors (M.C.B., H.F.L.) modified the MORE checklist to provide an applicable checklist for quality and bias assessment of the included studies (online suppl. Appendix II). Based on the MORE checklist, general descriptive elements, internal validity and external validity items were judged and defined as "OK," "minor flaw," "major flaw" or "poor reporting." We used the statistical software IBM SPSS version 21 for descriptive analysis of quality and bias assessment.

\section{Statistical Analysis}

We performed a random effect meta-analysis to estimate pooled incidence and prevalence rates with $95 \%$ CI. Heterogeneity was assessed using the $I^{2}$ statistics and visualized using prediction intervals. Meta-analysis of the incidence rates was performed using a Poisson-normal model [29]. To estimate pooled prevalence rates we applied the Freeman-Tukey transformation and performed a random effect meta-analysis on the transformed scale 


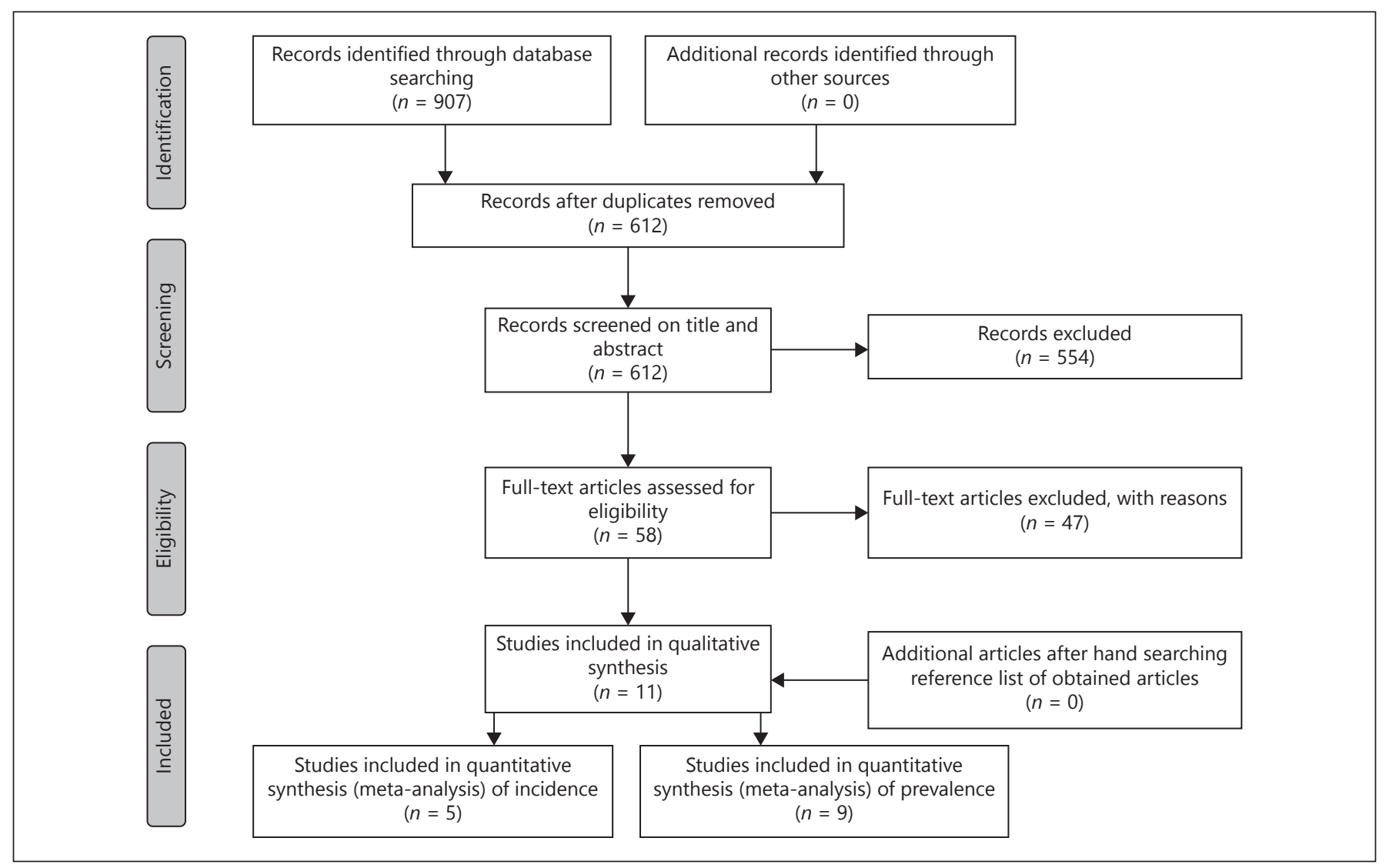

Fig. 1. Preferred Reporting Items for Systematic Reviews and Meta-Analyses (PRISMA) flowchart of the study selection process.

[30]. This transformation was necessary, since prevalence rates were close to zero. All statistical analyses were performed using $\mathrm{R}$ version 3.4.1., with the Metafor package version 2.0-0 used to perform the meta-analysis [31].

\section{Results}

We identified 907 articles in the initial search of which 295 duplicates were removed. Based on the title and abstract, 554 articles were excluded. After reviewing the full text of the remaining articles, 47 articles did not fulfil the following inclusion criteria: English language $(n=6)$, full text available $(n=3)$, reporting prevalence and/or incidence rates $(n=6)$, fulfilment of general accepted diagnostic criteria for CIDP $(n=3)$, original data $(n=28)$ and no duplication $(n=1)$. We contacted the corresponding authors of 2 studies because of missing data for conducting a meta-analysis; one author provided the required information (crude incidence rate, number of cases and person-years) [32]; one author could not provide the re- quired information [33]. Finally, we included 11 publications for this systematic review of which 9 studies were sufficient for meta-analysis of prevalence [9-13, 18, 34$36]$ and 5 studies [11, 13, 18, 32, 34] for meta-analysis of incidence (Fig. 1). One study determined prevalence and incidence twice by using different diagnostic criteria [18]. Of this study, only prevalence and incidence rates based on the EFNS/PNS 2006 criteria were included in the meta-analysis.

\section{Characteristics of Studies}

Most studies were conducted in Europe $(n=7)$ including the United Kingdom $(n=3)$, Republic of Ireland $(n=1)$, Italy $(n=1)$, Iceland $(n=1)$ and Norway $(n=1$; Table 1). The remaining studies were conducted in Australia $(n=1)$, Japan $(n=2)$ and the United States of America $(n=1)$. The population size in the studies varied between 135,802 and 127,655,000 patients. Person-years varied between 2,857,143 and 127,655,000. Six studies used the AAN criteria to define CIDP cases. In 4 studies, the EFNS/PNS criteria were used to confirm the diagno- 


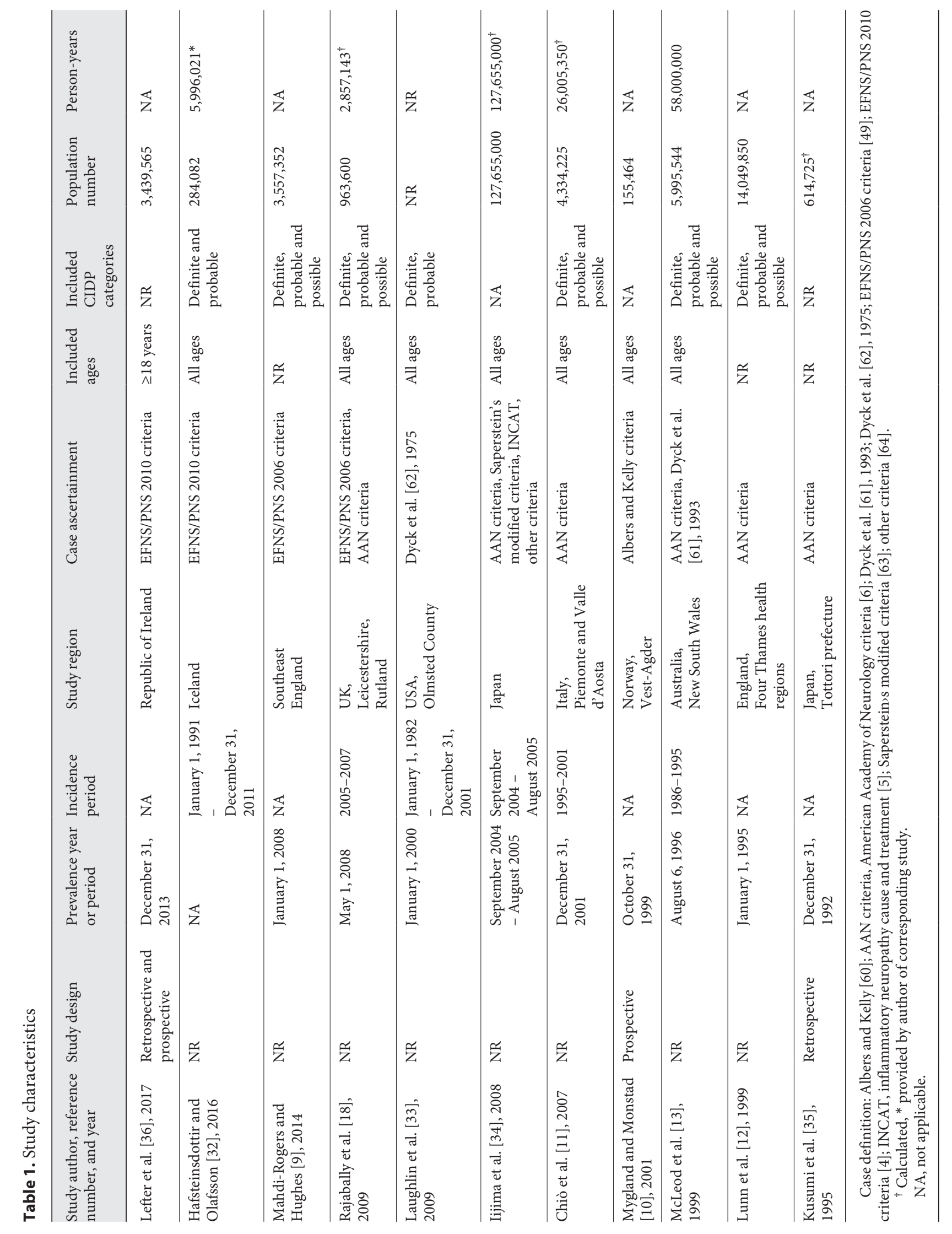


Table 2. Quality and bias assessment of included studies using MORE checklist

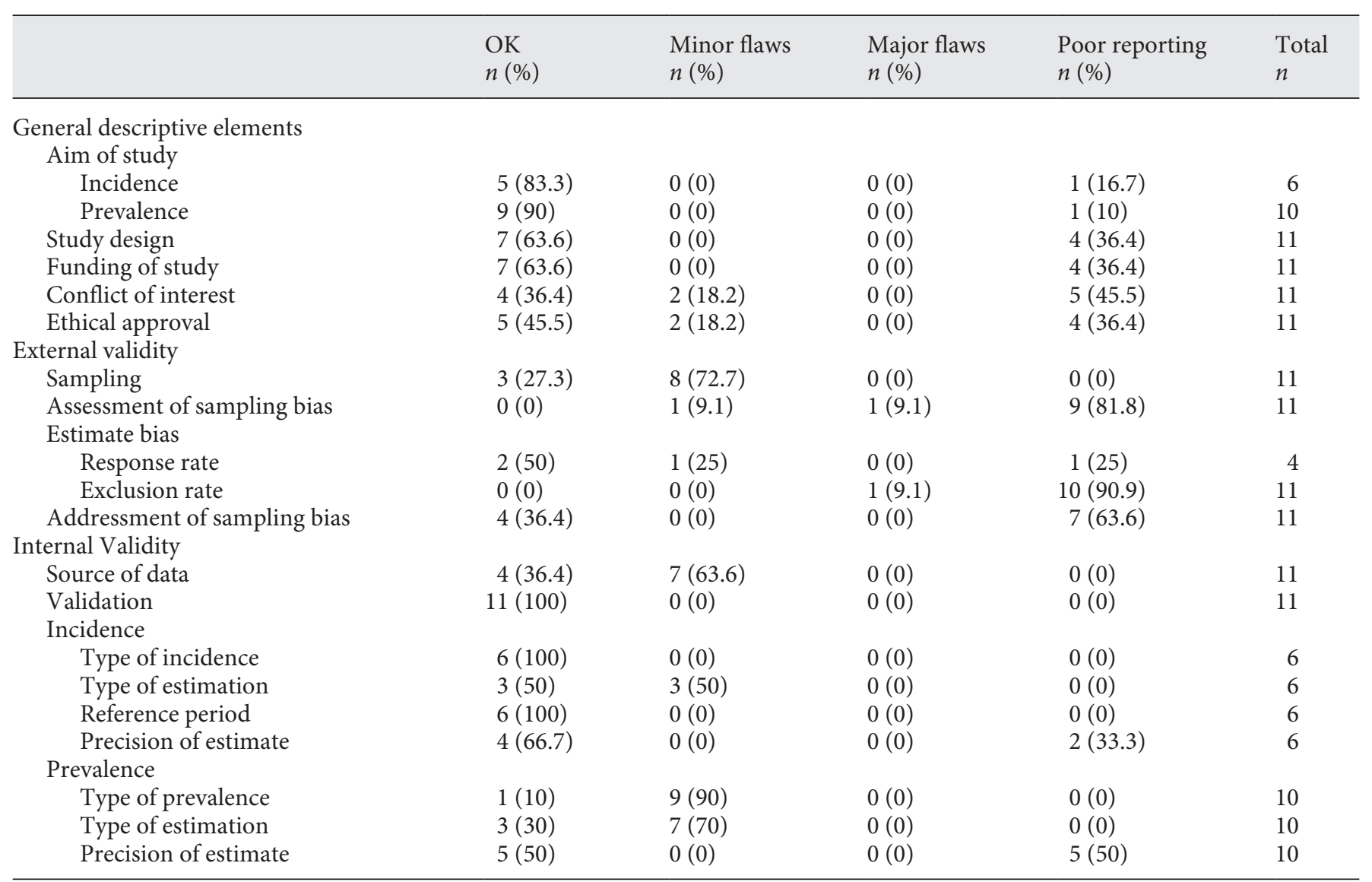

MORE checklist, methodological evaluation of observational research.

sis of CIDP; 2 studies used the EFNS/PNS 2006 criteria and the other 2 studies used the EFNS/PNS 2010 criteria. Most studies included all CIDP categories (definite, probable and possible CIDP), while 2 studies only included definite and probable CIDP. Years for which incidence rates were available varied from 1982 to 2011. Years for which the prevalence rates were available varied from 1992 to 2013.

\section{Methodological Quality of Studies}

Methodological quality varied between studies (Table 2). Measurement of incidence and prevalence rates was validated in all studies. We found minor flaws in the source of data due to crude incidence and prevalence rates and assessment of sampling bias $(n=1)$. We found major flaws in assessment of sampling bias $(n=1)$ and exclusion rate $(n=1)$. Poor reporting for assessment of sampling bias $(81.8 \%)$, addressment of sampling bias
(63.6\%) and exclusion rate (90.9\%) were found in most studies. No studies were excluded from the review based on insufficient methodological quality.

\section{Incidence}

We included 5 incidence studies in the meta-analysis of incidence $[11,13,18,32,34]$. In the meta-analysis of incidence, 818 cases and 220,513,514 person-years were included. Crude incidence rates varied between 0.15 and 0.70 cases per 100,000 person-years (Table 3 ). The pooled crude incidence rate for the total population is 0.33 per 100,000 person-years (95\% CI $0.21-0.53, I^{2}=95.7 \%$; prediction interval 0.11-0.98; Fig. 2). If we had included the estimated incidence based on the AAN criteria instead of based on the EFNS/PNS 2006 criteria of one study [18], the pooled incidence rate would have been 0.29 per 100,000 (95\% 0.20-0.43, $I^{2}=93.3 \%$; prediction interval $0.12-0.71)$. The pooled crude incidence rate for studies 
Table 3. Incidence rates

\begin{tabular}{|c|c|c|c|c|c|c|c|c|}
\hline $\begin{array}{l}\text { Study author, year, and } \\
\text { reference number }\end{array}$ & $\begin{array}{l}\text { Number } \\
\text { of cases }\end{array}$ & $\begin{array}{l}\text { Number } \\
\text { of male }\end{array}$ & $\begin{array}{l}\text { Number } \\
\text { of female }\end{array}$ & $\begin{array}{l}\text { Gender rate } \\
\text { ratio cases, } \\
\text { male/female }\end{array}$ & $\begin{array}{l}\text { Total incidence per } \\
100,000 \text { population } \\
(95 \% \mathrm{CI})^{*}\end{array}$ & $\begin{array}{l}\text { Male incidence per } \\
100,000 \text { population } \\
(95 \% \mathrm{CI})^{*}\end{array}$ & $\begin{array}{l}\text { Female incidence per } \\
100,000 \text { population } \\
(95 \% \mathrm{CI})^{*}\end{array}$ & $\begin{array}{l}\text { Gender rate ratio } \\
\text { incidence, male/ } \\
\text { female }\end{array}$ \\
\hline $\begin{array}{l}\text { Rajabally et al. [18], } 2009 \\
\text { EFNS/PNS } 2006 \text { criteria } \\
\text { AAN criteria }\end{array}$ & $\begin{array}{l}20 \\
10^{\dagger}\end{array}$ & $\begin{array}{r}13 \\
\mathrm{NR}\end{array}$ & $\begin{array}{r}7 \\
\mathrm{NR}\end{array}$ & $\begin{array}{l}1.9^{\dagger} \\
\text { NR }\end{array}$ & $\begin{array}{l}0.70(0.43-1.08) \\
0.35(0.17-0.64)\end{array}$ & $\begin{array}{l}0.92(0.49-1.58) \\
0.56(0.24-1.10)\end{array}$ & $\begin{array}{l}0.48(0.19-0.99) \\
0.14(0.02-0.50)\end{array}$ & $\begin{array}{l}1.9^{\dagger} \\
4.0^{\dagger}\end{array}$ \\
\hline Laughlin et al. [33], 2009 & NR & NR & NR & NR & $\begin{array}{l}1.4(0.8-2.0)^{!, * * *} \\
1.6(0.9-2.2)^{* * *}\end{array}$ & NR & NR & NR \\
\hline Iijima et al. [34], 2008 & 601 & 354 & 247 & $1.4^{\dagger}$ & 0.48 & 0.58 & 0.38 & $1.5^{\dagger}$ \\
\hline Chiò et al. [11], 2007 & 95 & NR & NR & NR & $\begin{array}{l}0.36(0.29-0.44) \\
0.34(0.28-0.42)^{* *}\end{array}$ & $0.51(0.39-0.65)$ & $0.22(0.15-0.31)$ & $2.3^{\dagger}$ \\
\hline
\end{tabular}

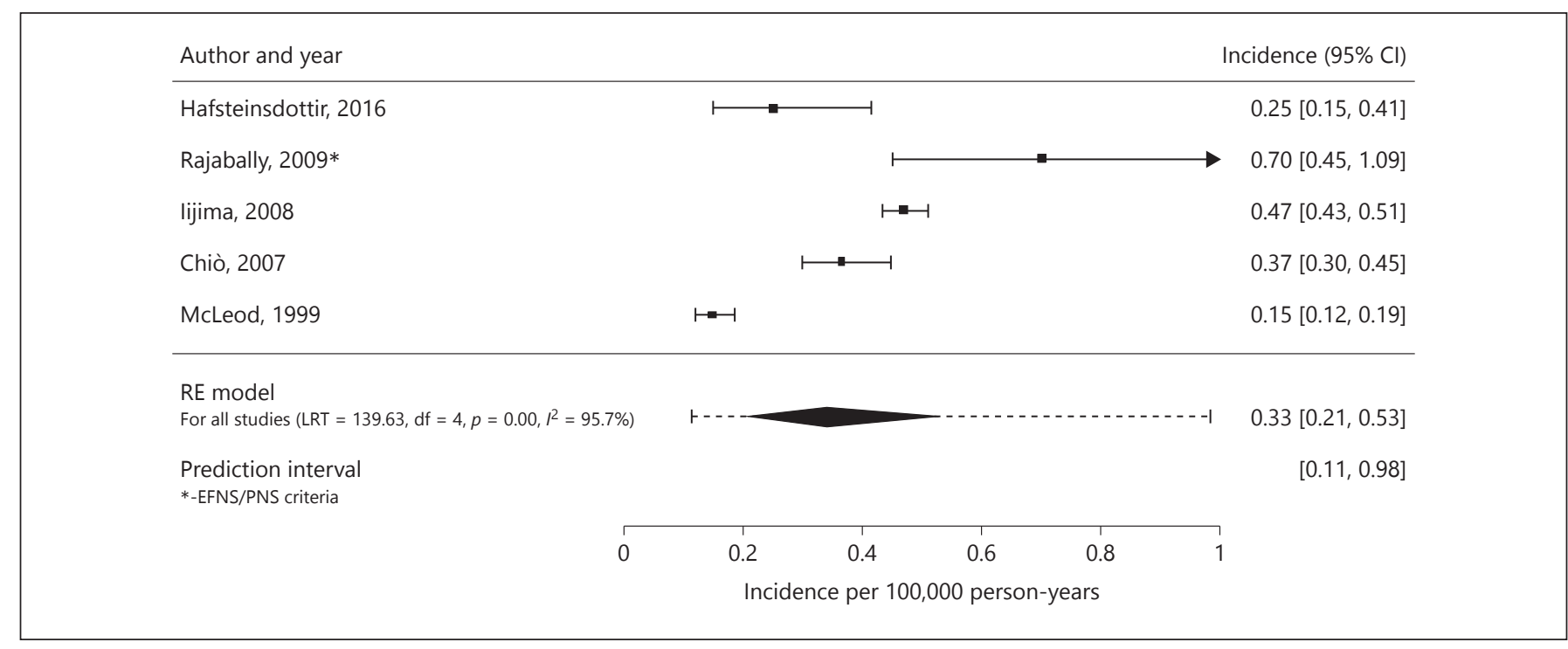

Fig. 2. Pooled crude incidence rate using the random-effects model. RE model, random-effects model.

using the AAN criteria is 0.36 per 100,000 person-years (95\% CI 0.30-0.44, $I^{2}=0.0 \%$; prediction interval 0.30 0.44). Data of studies using the EFNS/PNS 2006 and EFNS/PNS 2010 criteria was insufficient to conduct a crude pooled estimate for these criteria. Overall, the prediction intervals were substantially wider, thereby reflecting the observed heterogeneity between studies. In general, the reported crude incidence rates were higher in males than females (gender rate ratios varied between 1.5 and 4.0; Table 3). One study determined age-specific incidence rates [34]. The crude incidence rate in the age group of 15 years and older was 0.54 per 100,000 person-years (0.40 per 100,000 person-years in age-group of $15-55$ years and 0.73 per 100,000 person-years in the age-group older than 55 years) compared to a crude incidence rate of 0.06 per 100,000 person-years in age-group $0-15$ years. 
Table 4. Prevalence rates

\begin{tabular}{|c|c|c|c|c|c|c|c|c|}
\hline $\begin{array}{l}\text { Study author, year and } \\
\text { reference number }\end{array}$ & $\begin{array}{l}\text { Number } \\
\text { of cases }\end{array}$ & $\begin{array}{l}\text { Number } \\
\text { of male }\end{array}$ & $\begin{array}{l}\text { Number } \\
\text { of female }\end{array}$ & $\begin{array}{l}\text { Gender ratio } \\
\text { cases, male/ } \\
\text { female }\end{array}$ & $\begin{array}{l}\text { Total prevalence per } \\
100,000 \text { population } \\
(95 \% \mathrm{CI})^{*}\end{array}$ & $\begin{array}{l}\text { Male prevalence per } \\
100,000 \text { population } \\
(95 \% \mathrm{CI})^{*}\end{array}$ & $\begin{array}{l}\text { Female prevalence per } \\
100,000 \text { population } \\
(95 \% \text { CI })^{*}\end{array}$ & $\begin{array}{l}\text { Gender ratio } \\
\text { prevalence, } \\
\text { male/female }\end{array}$ \\
\hline $\begin{array}{l}\text { Mahdi-Rogers and Hughes } \\
\text { [9], } 2014\end{array}$ & 101 & 66 & 35 & $1.9^{\dagger}$ & $\begin{array}{l}2.84(2.31-3.45) \\
2.92(2.39-3.56)^{* *}\end{array}$ & $3.84(2.97-4.89)$ & $1.90(1.32-2.65)$ & $2.0^{\dagger}$ \\
\hline Laughlin et al. [33], 2009 & 11 & NR & NR & NR & $10.3(4.2-16.4)^{* * *}$ & NR & NR & NR \\
\hline Iijima et al. [34], 2008 & 2,433 & 1,495 & 938 & $1.6^{\dagger}$ & 1.61 & 2.01 & 1.23 & $1.6^{\dagger}$ \\
\hline Chiò et al. [11], 2007 & 155 & 105 & 50 & $2.1^{\dagger}$ & $\begin{array}{l}3.58(3.02-4.20) \\
3.41(2.92-3.98)^{* *}\end{array}$ & $5.02(4.13-6.10)$ & $2.23(1.65-2.94)$ & $2.3^{\dagger}$ \\
\hline Lunn et al. [12], 1999 & 94 & NR & NR & NR & 0.67 & NR & NR & NR \\
\hline Kusumi et al. [35], 1995 & 5 & 4 & 1 & $4.0^{\dagger}$ & 0.81 & 1.36 & 0.31 & $4.4^{\dagger}$ \\
\hline
\end{tabular}

\section{Prevalence}

We included 9 studies in the meta-analysis of prevalence rates $[9-13,18,34-36]$. In total, 3,160 cases and a population size of $160,765,325$ were included in the metaanalysis of prevalence. The crude prevalence rate varied between 0.67 and 7.7 cases per 100,000 persons (Table 4). The pooled crude prevalence rate for the total population is 2.81 per 100,000 ( $95 \%$ CI $1.58-4.39, I^{2}=99.1 \%$; prediction interval 0.12-8.78; Fig. 3). If we had included the estimated prevalence based on the AAN criteria instead of based on the EFNS/PNS 2006 criteria of one study [18], the pooled prevalence rate would have been 2.52 per 100,000 (95\% 1.41-3.95, $I^{2}=99.0 \%$; prediction interval $0.10-7.91)$. The pooled crude prevalence rate for studies using the AAN criteria is 1.59 per 100,000 (95\% CI $0.57-$ $3.11, I^{2}=96.7 \%$; prediction interval $\left.0.01-5.52\right)$. The pooled crude prevalence rate for studies using the EFNS/ PNS 2006 criteria is 3.67 per 100,000 (95\% CI 2.01-5.83, $I^{2}=87.2 \%$; prediction interval 1.18-7.52). While we find that studies using the EFNS/PNS 2006 criteria obtain higher prevalence rates than studies using the AAN criteria, the difference between the 2 estimates is not significant $(p=0.11)$. One study described prevalence using the EFNS/PNS 2010 criteria (5.87 per 100,000) [36]. Overall, the prediction intervals were substantially wider, thereby reflecting the observed heterogeneity between studies. In general, reported crude prevalence rates were higher in males than in females (gender rate ratios varied between 1.4 and 4.4; Table 4). Five studies determined age-specific prevalence rates $[9,11,13,18,34]$. Reported age-groups varied between studies. Overall, the prevalence increased with age (Table 5).

\section{Discussion}

Our meta-analysis provides a pooled crude incidence rate for CIDP of 0.33 per 100,000 (95\% CI 0.21-0.53; prediction interval $0.11-0.98)$ person-years and a pooled crude prevalence rate of 2.81 per 100,000 (95\% CI 1.58 4.39; prediction interval $0.12-8.78$ ) persons. Reported incidence and prevalence of CIDP showed substantial heterogeneity across studies. This heterogeneity may partly be explained by the use of different diagnostic criteria. Most CIDP patients were male and the incidence and prevalence of CIDP increased with age. We observed no evident geographical variation in the incidence or prevalence rates. 


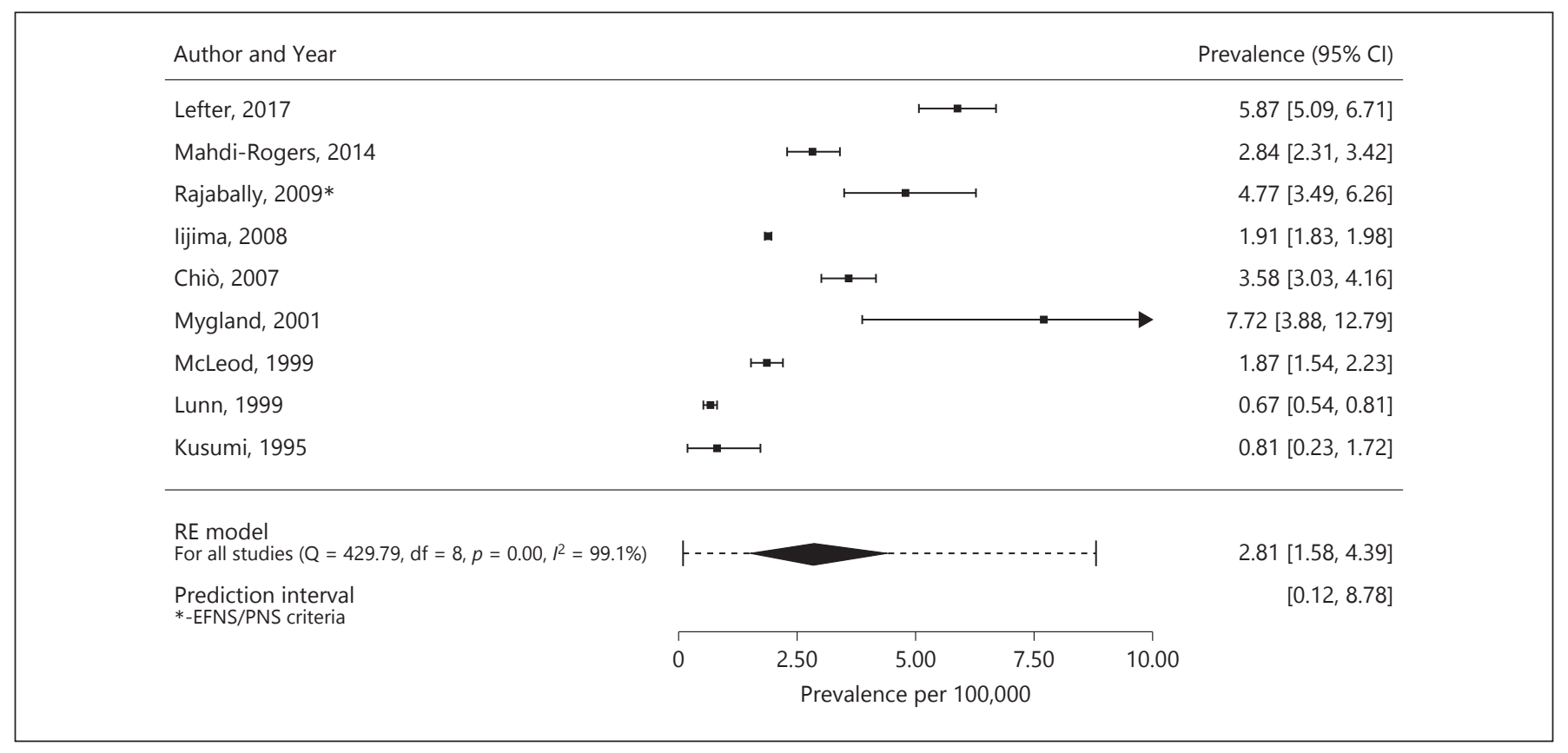

Fig. 3. Pooled crude prevalence rate using the random-effects model. RE model, random-effects model.

Interestingly, males are also overrepresented in other immune-mediated neuropathies including the GuillainBarré syndrome (GBS) and multifocal motor neuropathy $[9,37-40]$. The male predominance in these immunemediated neuropathies is unexplained and deviates from female predominance in many classic autoimmune disorders [41-43]. A male predominance has also been suggested for other forms of polyneuropathies, suggesting that males are more at risk to develop a polyneuropathy $[44,45]$. However, a recent comprehensive overview of the literature indicated that polyneuropathies in general are more common in females [15]. Older people seem to be more at risk to develop CIDP. An increasing incidence with age has also been demonstrated for GBS and polyneuropathies in general $[39,44]$.

The pooled incidence and prevalence rates should be read cautiously because of the substantial heterogeneity between the included studies. A critical determinant in these studies is the used case definition, since more than 15 different sets of diagnostic criteria for CIDP have been proposed in literature. Our meta-analysis suggests that studies using the AAN criteria found lower incidence and prevalence rates than studies using the EFNS/PNS 2006 criteria, and lower prevalence rates than studies using the EFNS/PNS 2010 criteria. One study determined prevalence and incidence rates for the AAN en EFNS/PNS 2006 criteria in the same population and found significantly (McNemar's exact test; $p<0.0001$ ) higher rates when using the EFNS/PNS 2006 criteria for prevalence (1.97 vs. 4.77 per 100,000$)$ and incidence $(0.35$ vs. 0.70 per 100,000$)$ [18]. These differences are likely related to the variation in sensitivity and specificity of these diagnostic criteria. The AAN criteria are considered most specific but are less sensitive presumably due to requirement of electrophysiological evidence of a minimum of 5 or 6 demyelinating findings in 2 nerves, and of abnormalities in cerebrospinal fluid and/or nerve biopsy studies for a diagnosis of definite CIDP [6, 46-48]. Overall, EFNS/PNS criteria have a higher sensitivity, likely because in contrast to the AAN criteria, only 1 or 2 demyelinating findings are required to diagnose CIDP, with or without additional testing, but are still highly specific presumably due to the higher thresholds for demyelinating features [6, 46-49]. The higher specificity and lower sensitivity of de AAN criteria seem to explain the reason behind the lower incidence and prevalence rates when using the AAN criteria. However, in our study, the difference between the pooled estimate using the AAN criteria and the pooled estimate using the EFNS/PNS 2006 criteria for prevalence was not significant, presumably due to the low number of prevalence studies using these criteria. The number of incidence studies using the AAN, EFNS/PNS 2006 and EFNS/ 
PNS 2010 criteria was insufficient to determine significance between studies using different criteria. Only one incidence study used the most recent EFNS/PNS criteria (2010) to confirm the diagnosis of CIDP. In contrast, this study found a lower incidence rate compared to studies using the AAN criteria, which may be explained by the exclusion of the category of patients with a "possible" CIDP in this study [32]. Of one study, we included estimates based on the EFNS/PNS 2006 criteria and excluded estimates based on the AAN criteria in the meta-analysis to avoid overrepresentation of this study in our sample [18]. We found no large differences in the pooled prevalence and incidence between only including estimates based on the AAN criteria or only including estimates based on the EFNS/PNS 2006 criteria of this study. The reported incidence and prevalence rates are also influenced by differences in inclusion and exclusion criteria between the studies. Particularly relevant is whether patients are included with additional diabetes mellitus or monoclonal gammopathy of undetermined significance. In addition, not all studies included the full range of ages of patient with CIDP. One study excluding patients younger than 18 years observed a relatively highly prevalence rate (5.87 per 100,000 adults; 95\% CI 5.06-6.68), that is probably explained by the increase of CIDP with age [36]. In conclusion, the use of different diagnostic criteria seems to affect the observed incidence and prevalence rates of CIDP but also differences in the use of other inclusion criteria seem to play a role. However, this should be read cautiously because significance between diagnostic criteria could not be demonstrated.

The prevalence of a disease depends on the disease duration. In clinical practice, it may be difficult to discriminate between patients with active disease and patients with residual nerve damage but inactive disease. The CIDP Disease Activity Status tool has been developed to define long-term outcomes in CIDP and to classify patients as cured if they have a stable neurological examination (either normal or abnormal) and are off all treatment for 5 or more years [50]. However, the concept of being cured in CIDP is questionable, because patients may relapse even years after the disease became inactive [50,51]. Most studies in our meta-analysis did not define the disease activity status or whether "cured" patients were excluded and this could have influenced the reported prevalence of CIDP. Long-term follow-up studies recording the disease activity status are needed to more accurately estimate the prevalence.

The observed incidence and prevalence rates may seem to increase in more recent studies, but no statistical

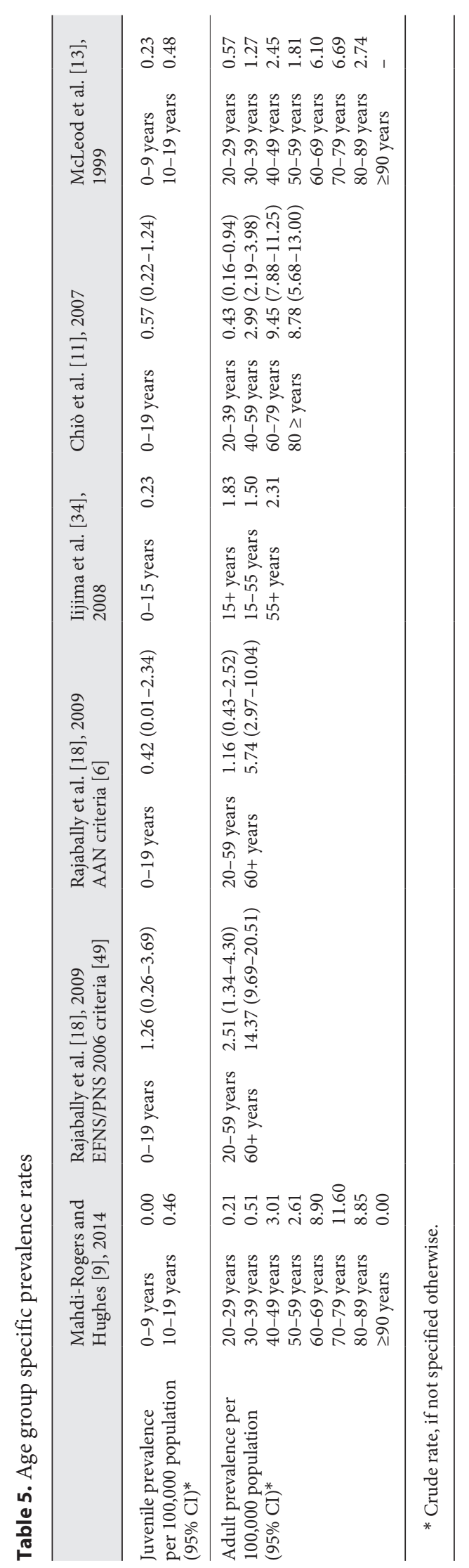

Neuroepidemiology 2019;52:161-172 DOI: $10.1159 / 000494291$
Incidence and Prevalence of CIDP:

A Systematic Review and Meta-Analysis 
significant trend in time for incidence is found $[32,33]$. Although the pathogenesis and aetiology of CIDP is far from understood, previous studies reported infections and vaccinations preceding the onset of CIDP symptoms [52-56]. Our pooled estimates of incidence and prevalence of CIDP can be used to assess changes of CIDP incidence following infections, vaccinations or other potential causal exposures, and to demonstrate a causal relation between preceding events and CIDP.

\section{Strength and Limitations}

A comprehensive literature search was performed by a biomedical information specialist and a medical doctor to ensure that most relevant published articles were captured. We used an evidence-based tool (Preferred Reporting Items for Systematic reviews and Meta-Analyses checklist) [19] to optimize the reporting of title, abstract, introduction, methods, results, discussion and funding of this systematic review and meta-analysis. To reduce diagnostic uncertainty, we excluded studies based on health insurance administrative claims (prevalence of 5.9 per $100,000)$ and not widely accepted diagnostic criteria (prevalence of 3-12 per 100,000; incidence of 2 per $100,000)$ for CIDP [57-59]. Overall, the quality of the included studies is moderate. Most studies reported a good internal validity. External validity and the quality of general descriptive elements could be improved. More attention to avoid sampling bias is needed in further incidence and prevalence of CIDP studies.

This systematic review and meta-analysis have some limitations. Most studies were performed in European countries. However, we found no difference in incidence and prevalence rates between European and non-European countries. Most studies used the former (2006) EFNS/

\section{Conclusion}

Our meta-analysis provides an estimate of the prevalence and incidence of CIDP and a starting point to better assess the social burden due to CIDP and to identify risk factors for developing CIDP, such as infections and vaccinations preceding the onset of CIDP symptoms. However, the observed heterogeneity between studies limits the application for future risk factor assessments. The use of different diagnostic criteria seems to explain in part the variation in reported prevalence and incidence rates and indicates the need to reach consensus of diagnostic criteria for CIDP. More high-quality studies are required to explain the heterogeneity, and to better estimate the prevalence and incidence of CIDP using the revised EFNS/PNS criteria.

\section{Acknowledgements}

We would like to thank Gerdien B. de Jonge, Biomedical Information Specialist at the Medical Library Erasmus MC, University Medical Center Rotterdam for her help in the literature search.

\section{Funding Sources and Disclosure Statement}

We would like to thank the Dutch Prinses Beatrix Spierfonds for funding (grant application number: W.OR16-18). B.C.J. has received unrestricted financial support for research from the Prinses Beatrix Spierfonds, GBS-CIDP Foundation International, Baxter Biopharmaceutics, CSL-Behring, Grifols and Annexon. PNS criteria. In addition, at present, the currently used EFNS/PNS (2010) criteria are being revised. The number of studies was too limited to conduct a proper comparison in phenotypes of CIDP between regions. We could not include one study (age- and sex-adjusted incidence 1.6 per 100,000 person-years; age- and sex-adjusted prevalence rate 10.3 per 100,000 persons) for meta-analysis because crude rates were not provided [33]. Including this study may have increased the pooled prevalence and incidence rates. In our meta-analysis, confidence intervals of the included studies sometimes differ from published CIs presumably due to different preferred calculation of confidence intervals. We may have missed relevant articles because we excluded non-English papers $(n=6)$, including studies conducted in France $(n=3)$, Germany $(n=1)$, Switzerland $(n=1)$ and Brazil $(n=1)$.

References
Neuroepidemiology 2019;52:161-172 DOI: $10.1159 / 000494291$
Broers/Bunschoten/Nieboer/Lingsma/ Jacobs
1 Vallat JM, Sommer C, Magy L: Chronic inflammatory demyelinating polyradiculoneuropathy: diagnostic and therapeutic challenges for a treatable condition. Lancet Neurol 2010;9:402-412.

2 Nobile-Orazio E: Chronic inflammatory demyelinating polyradiculoneuropathy and variants: where we are and where we should go. J Peripher Nerv Syst 2014;19:2-13.

3 Koller H, Kieseier BC, Jander S, Hartung HP: Chronic inflammatory demyelinating polyneuropathy. N Engl J Med 2005;352:13431356.

4 Joint Task Force of the EFNS and the PNS: European Federation of Neurological Societies/Peripheral Nerve Society Guideline on management of chronic inflammatory demyelinating polyradiculoneuropathy: report of a joint task force of the European Federation of Neurological Societies and the Peripheral Nerve Society - First Revision. J Peripher Nerv Syst 2010;15:1-9. 
5 Hughes R, Bensa S, Willison $\mathrm{H}$, Van den Bergh P, Comi G, Illa I, Nobile-Orazio E, van Doorn P, Dalakas M, Bojar M, Swan A; Inflammatory Neuropathy Cause and Treatment (INCAT) Group: Randomized controlled trial of intravenous immunoglobulin versus oral prednisolone in chronic inflammatory demyelinating polyradiculoneuropathy. Ann Neurol 2001;50:195-201.

6 Research criteria for diagnosis of chronic inflammatory demyelinating polyneuropathy (CIDP). Report from an Ad Hoc Subcommittee of the American Academy of Neurology AIDS Task Force. Neurology 1991;41:617618.

7 Bromberg MB: Review of the evolution of electrodiagnostic criteria for chronic inflammatory demyelinating polyradicoloneuropathy. Muscle Nerve 2011;43:780-794.

8 Oaklander AL, Lunn MP, Hughes RA, van Schaik IN, Frost C, Chalk CH: Treatments for chronic inflammatory demyelinating polyradiculoneuropathy (CIDP): an overview of systematic reviews. Cochrane Database Syst Rev 2017;1:CD010369.

9 Mahdi-Rogers M, Hughes RA: Epidemiology of chronic inflammatory neuropathies in southeast England. Eur J Neurol 2014;21:2833.

10 Mygland A, Monstad P: Chronic polyneuropathies in Vest-Agder, Norway. Eur J Neurol 2001;8:157-165.

11 Chio A, Cocito D, Bottacchi E, Buffa C, Leone M, Plano F, Mutani R, Calvo A; PARCIDP: Idiopathic chronic inflammatory demyelinating polyneuropathy: an epidemiological study in Italy. J Neurol Neurosurg Psychiatry 2007;78:1349-1353.

12 Lunn MP, Manji H, Choudhary PP, Hughes RA, Thomas PK: Chronic inflammatory demyelinating polyradiculoneuropathy: a prevalence study in south east England. J Neurol Neurosurg Psychiatry 1999;66:677-680.

13 McLeod JG, Pollard JD, Macaskill P, Mohamed A, Spring P, Khurana V: Prevalence of chronic inflammatory demyelinating polyneuropathy in New South Wales, Australia. Ann Neurol 1999;46:910-913.

14 Guptill JT, Bromberg MB, Zhu L, Sharma BK, Thompson AR, Krueger A, Sanders DB: Patient demographics and health plan paid costs in chronic inflammatory demyelinating polyneuropathy. Muscle Nerve 2014;50:47-51.

15 Hanewinckel R, van Oijen M, Ikram MA, van Doorn PA: The epidemiology and risk factors of chronic polyneuropathy. Eur J Epidemiol 2016;31:5-20.

16 Deenen JC, Horlings CG, Verschuuren JJ, Verbeek AL, van Engelen BG: The epidemiology of neuromuscular disorders: a comprehensive overview of the literature. J Neuromuscul Dis 2015;2:73-85.

17 Prevalence and Incidence of Rare Diseases: Bibliographic Data, O.R. Series, Editor, 2017.

18 Rajabally YA, Simpson BS, Beri S, Bankart J, Gosalakkal JA: Epidemiologic variability of chronic inflammatory demyelinating polyneuropathy with different diagnostic criteria: study of a UK population. Muscle Nerve 2009; 39:432-438.

19 PRISMA Preferred Reporting Items of Systematic Reviews and Meta-Analyses. http:// www.prisma-statement.org/ (cited 2017).

20 PROSPERO International Prospective Register of Systematic Reviews. https:// www.crd.york.ac.uk/PROSPERO/ (cited 2017).

21 Shamliyan TA, Kane RL, Ansari MT, Raman G, Berkman ND, Grant M, Janes G, Maglione M, Moher D, Nasser M, Robinson KA, Segal JB, Tsouros S: Development quality criteria to evaluate nontherapeutic studies of incidence, prevalence, or risk factors of chronic diseases: pilot study of new checklists. J Clin Epidemiol 2011;64:637-657.

22 Callan A, Capkun G, Vasanthaprasad V, Freitas R, Needham M: A systematic review and meta-analysis of prevalence studies of sporadic inclusion body myositis. J Neuromuscul Dis 2017;4:127-137.

23 Brazinova A, Rehorcikova V, Taylor MS, Buckova V, Majdan M, Psota M, Peeters W, Feigin V, Theadom A, Holkovic L, Synnot A: Epidemiology of traumatic brain injury in $\mathrm{Eu}-$ rope: a living systematic review. J Neurotrauma 2016, Epub ahead of print.

24 Manfredini D, Winocur E, Guarda-Nardini L, Paesani D, Lobbezoo F: Epidemiology of bruxism in adults: a systematic review of the literature. J Orofac Pain 2013;27:99110.

25 Stolwijk C, van Tubergen A, Castillo-Ortiz JD, Boonen A: Prevalence of extra-articular manifestations in patients with ankylosing spondylitis: a systematic review and meta-analysis. Ann Rheum Dis 2015;74: 65-73.

26 Manfredini D, Restrepo C, Diaz-Serrano K, Winocur E, Lobbezoo F: Prevalence of sleep bruxism in children: a systematic review of the literature. J Oral Rehabil 2013;40:631642 .

27 Edmondson D, Richardson S, Fausett JK, Falzon L, Howard VJ, Kronish IM: Prevalence of PTSD in survivors of stroke and transient ischemic attack: a meta-analytic review. PLoS One 2013;8:e66435.

28 Kayser SC, Dekkers T, Groenewoud HJ, van der Wilt GJ, Carel Bakx J, van der Wel MC, Hermus AR, Lenders JW, Deinum J: Study heterogeneity and estimation of prevalence of primary aldosteronism: a systematic review and meta-regression analysis. J Clin Endocrinol Metab 2016;101:2826-2835.

29 Stijnen et al: (2010). http://www.metaforproject.org/doku.php/analyses:stijnen 2010 (cited July 31,2017 ).

30 Miller (1978). http://www.metafor-project. org/doku.php/analyses:miller1978 [cited July 31, 2017].

31 Viechtbauer W: Conducting meta-analyses in $\mathrm{R}$ with the metafor package. J Stat Software 2010;36:1-48.
32 Hafsteinsdottir B, Olafsson E: Incidence and natural history of idiopathic chronic inflammatory demyelinating polyneuropathy: a population-based study in Iceland. Eur Neurol 2016;75:263-268.

33 Laughlin RS, Dyck PJ, Melton LJ 3rd, Leibson C, Ransom J, Dyck PJ: Incidence and prevalence of CIDP and the association of diabetes mellitus. Neurology 2009;73:39-45.

34 Iijima M, Koike H, Hattori N, Tamakoshi A, Katsuno M, Tanaka F, Yamamoto M, Arimura K, Sobue G; Refractory Peripheral Neuropathy Study Group of Japan: Prevalence and incidence rates of chronic inflammatory demyelinating polyneuropathy in the Japanese population. J Neurol Neurosurg Psychiatry 2008;79:1040-1043.

35 Kusumi M, Nakashima K, Nakayama $H$, Takahashi K: Epidemiology of inflammatory neurological and inflammatory neuromuscular diseases in Tottori Prefecture, Japan. Psychiatry Clin Neurosci 1995;49:169-174.

36 Lefter S, Hardiman O, Ryan AM: A population-based epidemiologic study of adult neuromuscular disease in the Republic of Ireland. Neurology 2017;88:304-313.

37 Vlam L, van der Pol WL, Cats EA, Straver DC Piepers S, Franssen H, van den Berg LH: Multifocal motor neuropathy: diagnosis, pathogenesis and treatment strategies. Nat Rev Neurol 2011;8:48-58.

38 Willison HJ, Jacobs BC, van Doorn PA: Guillain-Barre syndrome. Lancet 2016;388:717727.

39 Sejvar JJ, Baughman AL, Wise M, Morgan OW: Population incidence of Guillain-Barre syndrome: a systematic review and metaanalysis. Neuroepidemiology 2011;36:123133.

40 Cats EA, van der Pol WL, Piepers S, Franssen $\mathrm{H}$, Jacobs BC, van den Berg-Vos RM, Kuks JB, van Doorn PA, van Engelen BG, Verschuuren JJ, Wokke JH, Veldink JH, van den Berg LH: Correlates of outcome and response to IVIg in 88 patients with multifocal motor neuropathy. Neurology 2010;75:818-825.

41 Patel R, Shahane A: The epidemiology of Sjogren's syndrome. Clin Epidemiol 2014;6:247255

42 Trojano M, Lucchese G, Graziano G, Taylor BV, Simpson S Jr, Lepore V, Grand'maison F, Duquette $P$, Izquierdo G, Grammond P, Amato MP, Bergamaschi R, Giuliani G, Boz C, Hupperts R, Van Pesch V, Lechner-Scott J, Cristiano E, Fiol M, Oreja-Guevara C, Saladino ML, Verheul F, Slee M, Paolicelli D, Tortorella C, D'Onghia M, Iaffaldano P, Direnzo V, Butzkueven H; MSBase Study Group and the New Zealand MS Prevalence Study Group: Geographical variations in sex ratio trends over time in multiple sclerosis. PLoS One 2012; 7:e48078.

43 Rees F, Doherty M, Grainge MJ, Lanyon P, Zhang W: The worldwide incidence and prevalence of systemic lupus erythematosus: a systematic review of epidemiological studies. Rheumatology (Oxford) 2017;56:1945-1961.
Incidence and Prevalence of CIDP:

A Systematic Review and Meta-Analysis
Neuroepidemiology 2019;52:161-172 DOI: $10.1159 / 000494291$ 
44 Visser NA, Notermans NC, Linssen RS, van den Berg LH, Vrancken AF: Incidence of polyneuropathy in Utrecht, the Netherlands. Neurology 2015;84:259-264.

45 Deenen JC, van Doorn PA, Faber CG, van der Kooi AJ, Kuks JB, Notermans NC, Visser LH, Horlings CG, Verschuuren JJ, Verbeek AL, van Engelen BG: The epidemiology of neuromuscular disorders: age at onset and gender in the Netherlands. Neuromuscul Disord 2016;26:447-452.

46 Breiner A, Brannagan TH 3rd: Comparison of sensitivity and specificity among 15 criteria for chronic inflammatory demyelinating polyneuropathy. Muscle Nerve 2014;50:40-46.

47 Rajabally YA, Nicolas G, Pieret F, Bouche P, Van den Bergh PY: Validity of diagnostic criteria for chronic inflammatory demyelinating polyneuropathy: a multicentre European study. J Neurol Neurosurg Psychiatry 2009; 80:1364-1368.

48 Tackenberg B, Lunemann JD, Steinbrecher A, Rothenfusser-Korber E, Sailer M, Bruck W, Schock S, Zschenderlein R, Zipp F, Sommer N: Classifications and treatment responses in chronicimmune-mediated demyelinatingpolyneuropathy. Neurology 2007;68:1622-1629.

49 Hughes RA, Bouche P, Cornblath DR, Evers E, Hadden RD, Hahn A, Illa I, Koski CL, Leger JM, Nobile-Orazio E, Pollard J, Sommer C, Van den Bergh P, van Doorn PA, van Schaik IN: European Federation of Neurological Societies/Peripheral Nerve Society guideline on management of chronic inflammatory demyelinating polyradiculoneuropathy: report of a joint task force of the European Federation of Neurological Societies and the Peripheral Nerve Society. Eur J Neurol 2006; 13:326-332.

50 Gorson KC, van Schaik IN, Merkies IS, Lewis RA, Barohn RJ, Koski CL, Cornblath DR, Hughes RA, Hahn AF, Baumgarten M, Goldstein J, Katz J, Graves M, Parry G, van Doorn PA: Chronic inflammatory demyelinating polyneuropathy disease activity status: recommendations for clinical research standards and use in clinical practice. J Peripher Nerv Syst 2010;15:326-333.

51 Albulaihe H, Alabdali M, Alsulaiman A, Abraham A, Breiner A, Barnett C, Katzberg HD, LovblomLE, Perkins BA, Bril V:Diseaseactivity in chronic inflammatory demyelinating polyneuropathy. JNeurol Sci 2016;369:204-209.

52 McCombe PA, Pollard JD, McLeod JG: Chronic inflammatory demyelinating polyradiculoneuropathy. A clinical and electrophysiological study of 92 cases. Brain 1987;110(Pt 6):1617-1630.

53 Gorson KC, Allam G, Ropper AH: Chronic inflammatory demyelinating polyneuropathy: clinical features and response to treatment in 67 consecutive patients with and without a monoclonal gammopathy. Neurology 1997;48:321-328.

54 Leonhard SE, Munts AG, van der Eijk AA, Jacobs BC: Acute-onset chronic inflammatory demyelinating polyneuropathy after Zika virus infection. J Neurol Neurosurg Psychiatry 2018;89:1118-1119.

55 da Silva IRF, Frontera JA, Bispo de Filippis AM, Nascimento OJMD; RIO-GBS-ZIKV Research Group: Neurologic complications associated With the Zika Virus in Brazilian adults. JAMA Neurol 2017;74:1190-1198.
56 Kuitwaard K, Bos-Eyssen ME, BlomkwistMarkens PH, van Doorn PA: Recurrences, vaccinations and long-term symptoms in GBS and CIDP. J Peripher Nerv Syst 2009; 14: 310-315

57 Bril V, Blanchette CM, Noone JM, Runken MC, Gelinas D, Russell JW: The dilemma of diabetes in chronic inflammatory demyelinating polyneuropathy. J Diabetes Complications 2016;30:1401-1407.

58 Kandil MR, Darwish ES, Khedr EM, Sabry MM, Abdulah MA: A community-based epidemiological study of peripheral neuropathies in Assiut, Egypt. Neurol Res 2012;34: 960-966.

59 Rudolph T, Farbu E: Hospital-referred polyneuropathies-causes, prevalences, clinicaland neurophysiological findings. Eur J Neurol 2007;14:603-608.

60 Albers JW, Kelly JJ Jr: Acquired inflammatory demyelinating polyneuropathies: clinical and electrodiagnostic features. Muscle Nerve 1989;12:435-451

61 Dyck PJ, Thomas PK, Griffin JW, editors. Peripheral Neuropathy, ed 3. Philadelphia, WB Saunders, 1993.

62 Dyck PJ, Lais AC, Ohta M, Bastron JA, Okazaki H, Groover RV: Chronic inflammatory polyradiculoneuropathy. Mayo Clin Proc 1975;50:621-637.

63 Saperstein DS, Katz JS, Amato AA, Barohn RJ: Clinical spectrum of chronic acquired demyelinating polyneuropathies. Muscle Nerve 2001;24:311-324.

64 Sander HW, Latov N: Research criteria for defining patients with CIDP. Neurology 2003; 60(8 suppl 3):S8-S15. 